\title{
Investigation of Relationship between Customer Relationship Management Dimensions and Organizational Productivity
}

\author{
Hossein Vazifehdoost
}

Department of Business Management, Science and Research Branch, Islamic Azad University, Tehran, Iran

Fatollah Toluei

Department of Industrial Management, State Management Training Center, Tehran, Iran Corresponding Author Email: F_t8021@yahoo.com

Tohid Alizadeh Hossein Hajlou

Educator, Department of Business Management, Payam Noor University, Po. BOX 19395-3697, Tehran, Iran

\section{Doi:10.5901/mjss.2014.v5n23p2701}

\section{Abstract}

The present research aims to investigate relationship between dimensions of customer relationship management (CRM) and organizational productivity. Statistical population of the present research included all employees of Mellat Bank in Ardebil Province, Iran. Questionnaire was used for data collection. Simple random sampling method was used for picking saple members. 145 employees were selected as sample size and received questionnaires. Because distribution of statistical population was not normal, Spearman non-parametric test was used. Finally, all research hypotheses were verified. In other words, technology, employees' management, individual services, system integration and organizational culture had significant relationships with organizational productivity.

Keywords: technology, employees' management, individual services, system integration, organizational culture, organizational productivity

\section{Introduction}

Undoubtedly, customers are considered as the most important asset for every organization. Customers are resources for industry threats and opportunities because of direct relationship they have with organizational performance. In new business era, customers' satisfaction attraction is very vital and senior managers know well that their success in achieving organizational targets depends on customers' satisfaction (Abbasi\&Torkaman, 2010). Customers' satisfaction is a result of comparison between pre-purchase expectations and perceived real performance (Aghazadeh, Moghanlou and Rahnama, 2012). In any organization, whether production or service, customer is the most important factor in organizational survival and if $\mathrm{n}$ organization fails to attract customer's satisfaction, it will not be continued for long (Vazifehdoost, Rahnama\&Mousavian, 2014). It seems necessary to manage customer relationship properly in any organization (especially domestic organizations) and also design software for implementation of this strategy. Furthermore, because CRM is a relatively new concept in IT industry, every organization needs to implement CRM systems in order to survive in competition and improve productivity (Behi, 2004). CRM is a commercial strategy which deals with absorption, maintenance and promotion of customer. If CRM is implemented, organizations will be able to carry out the above three tasks and therefore keep their main source of competitive advantage which is the very customer. This will not possible without application of information and communications technology (ICT) in globalization era in which an organization might have millions of customers. ICT is an instrument for implementation of ICT and helps organizations with establishing relationship with all customers. Within the past decade, we have been confronted with rapid changes in commerce arena. As these changes speed increases as a result of changes in technology, free and close activity of global markets, increase in innovation, continuous reduction in products lifecycles and elimination of spatial and temporal distances, organizations have been confronted with markets which are very fiercely competitive and customers' needs are increasing (SamimiAmlashi, 2007). CRM responds to managers' needs for competition. However, there are many reports of CRM failures and this makes companies to be doubtful about investing in CRM systems. 
Although CRM software market was expected to increase from 7 billion dollars in 2000 to more than 32 billion dollars in 2006, studies showed that 30 to $50 \%$ of CRM activities fail to yield expected results and go waist (SamimiAmlashi, 2007).

\section{Research Theoretical Literature}

\subsection{Customer Relationship Management (CRM)}

CRM was first introduced in 1980s and was based upon attraction, maintenance and increase in customers' satisfaction. Then, in 1990s, new type of CRM was propounded again as an instrument for "a business strategy for selection and management of the most valuable type of CR". Since then, CRM received a lot of attention and great software companies have developed many software for CRM (Behi, 2004). Today, banks are obliged to establish relationship with customers and try to understand customers' demands and try to satisfy customers and banks which pay attention to customers' loyalty consider customer maintenance as important (Rahnama et al, 2012). CRM is a business process which emphasizes on all customer characteristics and identifies customers' behavioral model and results in customer knowledge. CRM helps establish long-term relationship with customers and influences on their perception of organizational services or products. CRM, from one viewpoint, has been defined by four elements of a simple framework: knowledge, target, sales and service (Rygielsk, 2002). Customer management, customer information system, customer value management, care for customer, customer orientation or customer-oriented management are different names for CRM concept(Thompson, 2002). CRM is one of the hottest subjects in the field of business strategy, market management and IT. CRM is also based upon a multidisciplinary philosophy which requires integration in business. Therefore, successful implementation of CRM is very difficult (Piccoli et al, 2003).

Many companies have problems with understanding CRM. They think they can use advantages of CRM if the implement it but this is not true. Companies will be successful in implementation of CRM only when they adopt customeroriented business strategies and then try to implement CRM systems. Another reason for confrontation of companies with problems is that no salesperson provides all CRM needs which is necessary for company. Of course, CRM is not only a technology or service but also it is a strategy which is enabled by technology. If an organization wants to implement CRM strategy, this strategy involves marketing, sale, services, databases and technology as well as other internal factors (like individuals culture and environment). In fact, there must be a comprehensive plan so that every person tasks are clarified and the organization can reach integrated targets and better relationships (Reynolds, 2002). Today, there are many definitions for CRM:

- Spread of customers' information across an organization, formulation of some strategies and special techniques for satisfaction of market needs and presence of a sense of commitment to related plans all over the organization (Shapiro, 1985).

- Customer orientation means collection of information on customers and use of this information in business units (Behi, 2004).

- Customer orientation is a type of organizational culture which creates behaviors necessary for valuation of customers in its best and most beneficent form (Behi, 2004).

- Customer orientation is a tendency to collect information on customers and use of the info in formulation of strategy in order to satisfy these needs and implementation of this strategy via responding to customers' needs (Behi, 2004).

\subsection{Organizational culture}

Culture, in its widest meaning, refers to complex human products like arts, philosophy, knowledge and technology and in social sciences, it refers to a system of common rules which are accepted by a group of people at a particular time and group behaviors is conducted based upon this system (Tousi, 2003). Organization also refers to a collection of people which cooperate for achieving common objectives. An organization is a cultural phenomenon and every organization has a special culture. Moreover, culture is a word which is used for organizations analysis. A manager is the symbol of an organization and the role of traditions and customs, stories, fables and organizational symbols is important (Rezaeeyan, 2011). By organizational culture, we mean a common understanding of an organization shared by employees and this characteristic differentiates two organizations. JreeceArgric defines organizational culture as living system and believes that it is a common behavior, way for thinking in reality and a method for real common behavior. It can be said that all individuals who have studied culture unanimously agree that culture reflects an organization's history and concerns 
human studies like study of customs and entities and it is formed by a group of individuals. Its movement is slow and difficult.

\subsection{Organizational integration}

Organizational information accessibility is necessary for interaction with customers. Distribution of this information can be internal or external. Internal information transfer concerns distribution of information in an organization in order to improve customer support level. Furthermore, external transport of information is use of customer and organization information in order to increase processes for interaction with customers and improvement of services (Wells et al, 1999).

\subsection{Employees}

Within the past two decades, "human resource strategic management" is emphasized in scientific texts and employees are considered as partners for organizational success. Organizations have to consider employees as valuable assets and internal customers in order to reach their targets. Therefore, organizations must train and motivate their employees in order to achieve competitive advantage and long-term targets (omidvariyan, 2006). In order to keep an organization effective, managers must have special capabilities, skills, experiences and socio-communicational talents and in order to have an effective management, we must start from targets and managers must first rely on their resources and specially human resources (Rahnama et al, 2011).

\subsection{Service personalization}

The main focus of CRM is on establishment of closer and deeper relationship with customers and increasing organizational power. This is because present customers are more profitable than future potential customers and selling products to present customers is inexpensive. Attraction of customers is improved as products and levels of services are coordinated (Pappard, 2000).

\subsection{IT and CRM}

ICT was introduced in 1990s and developed rapidly. This technology is basically different from other technologies and not only influences on its area but also it facilitates economic and non-economic activities and improves efficiency and productivity. One of the greatest challenges ahead of organizations is use of web-based technologies. Internet is a new channel for economic transactions and making income. Rapid development of e-commerce and internet and financial and banking sectors, customers are becoming more and more interested in use of online banking. Development and facilitation of access to monetary services is one of the greatest achievements of banking system in the world (Abdolvand et $\mathrm{al}, 2012)$. The present era is the age of unpredictable changes and companies are confronted with issues like elimination of borders of markets, fragmentation of markets, short products lifecycle, rapid changes in customers' purchase model and so on in competition (Rahnama et al, 2012). Exact customers' information is necessary for successful performance of CRM and technology lays an important role in organizational smartness for implementation of CRM strategy (Omidvariyan, 2006). Use of information technology has many advantages in CRM. In the following sentences, we deal with main advantages of use of IT in CRM:

1. Increase in customer's loyalty: an effective eCRM system can establish relationship with customers with a constant trend (without attention to relationship channel). Information collected by eCRM system helps an organization with identification of real costs of customer maintenance. This information enables an organization to allocate its resources and time to the most profitable customers. Considering the fact that the same behavior towards all customers is incorrect, classification of the best customers enables organizations to manage customers' affairs effectively. These actions increase customers' loyalty. One of the instruments which is used by organizations in order to increase customer's loyalty is personalization (Greenberg, 2001). CRM software can generate information for customers which are extracted from different resources like customers' data bank pr transaction system. A transaction system is a system which registers previous transactions information. In any e-purchase, this system provides the best suggestion for the customer based on its previous information. Moreover, personalization concept is a mechanism for avoiding waste of time. A personalized system can display site advertisements and contents based on customers' interest. For instance, Amazon website proposes similar items for purchasers. This process adds value to customers. 
2. Effective marketing: using eCRM, we can have information on every customer. Having detailed information on a customer enables an organization to predict a customer's favorable product and his or her purchase schedule. This key information enables an organization to survive in competition and be powerful in marketing and sale (Mostaghel, 2006).

3. Improvement of customer services and support: use of IT in a comprehensive eCRM system can create a bank of customer information and help an organization with establishing relationship with customers. Therefore, useless contacts of customers with the organization is reduced and this results in better service and more powerful support.

4. Higher efficiency and reduction in costs: one of the other advantages of CRM is reduction in transactions cost (Romano, 2002). Data storage and recovery by eCRM can help reduce human force and other costs. Collection of customers' data in an info bank enables marketing and sales section to share information and take steps towards common targets (Mostaghel, 2006). eCRM play effective roles in financial efficiency using cost tracking, better recognition of costs and contribution to capital return indices.

\subsection{Productivity}

The word "productivity" maybe first was introduced in a paper published by an individual called "Quesnay" in 1766. After more than a century, i.e. in 1883, Larous dictionary states that a person called Littre defined productivity as follows: "power and ability to produce". In this definition, productivity refers to eagerness for production. Since early $20^{\text {th }}$ century, this word referred to relationship between efficiency (output) and used factors and instruments for production (input). A person called "Early" defined productivity as relationship between efficiency and used instruments for production of this efficiency in 1900. In 1950, "Organization for European Economic Cooperation (OEEC)" presented a more complete definition for productivity:

Productivity is the ratio of efficiency (output) to one of the production factors. According to definition provided by European productivity Agency, productivity is an intellectual viewpoint which tries to improve what is present. Therefore, productivity is based on this belief that human can do his or her works better than before. According to another definition for productivity, it means doing right things plus doing things right (Hoseini, 2011). Therefore, we can refer to capital productivity, investment productivity, raw material productivity, depending on capital output, investment output or raw material output (Abtahi and Kazemi, 1996). Today, organizations pay special attention to their employees because experience has it that as external and material needs are satisfied, the internal needs and psychological needs are satisfied. Dissatisfaction of such needs reduces efficiency and effectiveness (productivity) very much and this makes employees alienated and reduces tendency to work (Khoshpanjeh et al, 2012). Productivity is a criterion of services and products outputs over workforce input, material input and equipment input. As an industry is more productive, it is more competitive. When productivity increases, firms can pay higher wages without increasing inflation. Productivity improves life standards and productivity improvement means obtaining more output from same inputs. It does not mean increase in production via money, time and individuals but it means working better with what we have. Improvement of productivity does not mean working hard but also it means working smartly. Present worldnecessitates that we produce more total out of lower individuals, space and time (Cascio, 1998). 


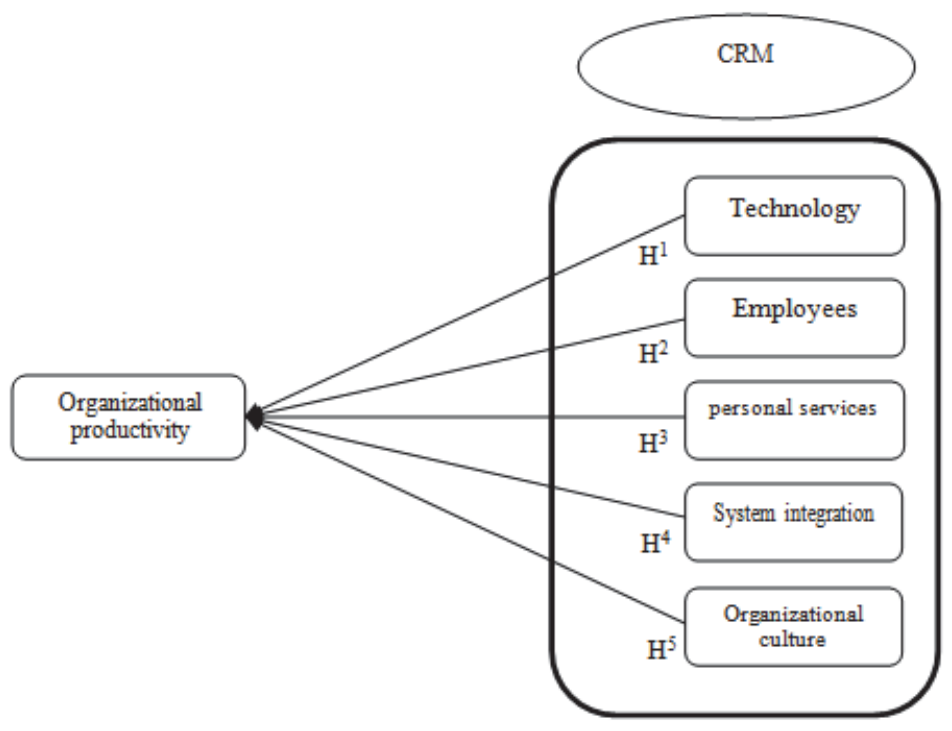

Figure 1. Research conceptual model

Considering the research conceptual model, the following hypotheses are proposed:

- There is a significant relationship between technology (a dimension of CRM) and organizational productivity.

- There is a significant relationship between employees' management (a dimension of CRM) and organizational productivity.

- There is a significant relationship between personal services (a dimension of CRM) and organizational productivity.

- There is a significant relationship between system integration (a dimension of CRM) and organizational productivity.

- There is a significant relationship between organizational culture (a dimension of CRM) and organizational productivity.

\subsection{Questionnaire}

Questionnaire was used for data collection. The questionnaire was based on 5-point Likert scale from "very low" to "very much". After preparation of the questionnaire, 25 questionnaires were distributed among customers in order to test the reliability of the questionnaire. Chronbach's alpha was used for investigation of reliability. Results showed that alpha value was above 0.7 for all variables. Further, questionnaire validity was verified by experts. Therefore, the questionnaire had enough validity and reliability to be distributed among respondents.

\subsection{Sample}

Statistical population of the research included all employees of different branches of Mellat Bank in Ardebil Province, Iran (320 employees). 85 of these employees were managers and assistants and after setting them aside, 235 employees constituted population size. According to Krejcie Morgan table, sample size was 145 people. Considering the scattering of employees all over Ardebil Province (153 people in Ardebil City and 71 people in other cities), the population was divided into two clusters and after determination of the share of each cluster considering sample size, the questionnaires were randomly distributed among members. Demographic information of respondents are summarized in table 1. 
Table 1. Demographic information

\begin{tabular}{|c|c|c|c|}
\hline Frequency percentage & Frequency & Dimensions & Variable \\
\hline 94.5 & 137 & male & \multirow{2}{*}{ gender } \\
\hline 5.5 & 8 & female & \\
\hline 9.7 & 14 & single & \multirow{2}{*}{ Marital status } \\
\hline 90.3 & 131 & married & \\
\hline 13.1 & 19 & Below 30 & \multirow{4}{*}{ age } \\
\hline 25.5 & 37 & $30-35$ & \\
\hline 29.0 & 42 & $36-40$ & \\
\hline 32.4 & 47 & 41 and above & \\
\hline 12.4 & 18 & Below high school degree & \multirow{4}{*}{ education } \\
\hline 15.2 & 22 & Associate's degree & \\
\hline 57.9 & 84 & bachelor & \\
\hline 14.5 & 21 & Master and above & \\
\hline
\end{tabular}

\section{Data Analysis and Hypotheses Test}

\subsection{Investigation of normality of variables}

In order to investigate normality of the variables, Kolmogrov-Smearnov test was used. Results of this test have been summarized in table 2.

\begin{tabular}{|c|c|c|c|}
\hline Sig. level & $d f$ & Static & Variables \\
\hline 0.000 & 145 & 0.124 & Technology \\
\hline 0.000 & 145 & 0.130 & Employees \\
\hline 0.000 & 145 & 0.128 & Personal services \\
\hline 0.000 & 145 & 0.121 & System integration \\
\hline 0.000 & 145 & 0.099 & Organizational culture \\
\hline 0.000 & 145 & 0.119 & Organizational productivity \\
\hline
\end{tabular}

As it can be seen, all variables have non-normal distribution because significance level of the variables are lower than 0.05. therefore, non-parametric tests were used for hypotheses analyses.

\subsection{Investigation of organizational productivity in Mellat Bank}

Considering the non-normal distribution of organizational productivity, binomial test was used for investigation of productivity. Results of this test have been summarized in table 3.

Table 3: binomial test for organizational productivity

\begin{tabular}{|cc|c|c|c|c|c|}
\hline & & Category & $\mathrm{N}$ & Observed Prop. & Test Prop. & Exact Sig. (1-tailed) \\
\hline \multirow{4}{*}{ Productivity } & Group 1 & $<=3$ & 47 & .3 & .5 & $.000^{\mathrm{a}}$ \\
& Group 2 & $>3$ & 98 & .7 & & \\
& Total & & 145 & 1.0 & & \\
\hline
\end{tabular}

Considering the above information obtained from binomial test, it can be seen that Sig value is smaller than alpha= 0.05 . therefore, in $95 \%$ of certainty, we can conclude that Mellat Bank employees are in appropriate condition in terms of organizational productivity (above 3).

\subsection{Research hypotheses test}

In order to test the hypotheses, correlating test was used. Spearman correlation test was used because of non-normal variables. Results of the hypotheses test using Spearman correlation test are summarized in table 4. 
Table 4: research hypotheses test

\begin{tabular}{|c|c|c|c|}
\hline Result & (Sig) & Correlation coefficient & Hypothesis \\
\hline Hypothesis supported & 0.000 & 0.421 & $\begin{array}{l}\text { - There is a significant relationship between technology (a } \\
\text { dimension of CRM) and organizational productivity. }\end{array}$ \\
\hline Hypothesis supported & 0.000 & 0.463 & $\begin{array}{l}\text { - There is a significant relationship between employees' } \\
\text { management (a dimension of CRM) and organizational } \\
\text { productivity. }\end{array}$ \\
\hline Hypothesis supported & 0.000 & 0.573 & $\begin{array}{l}\text { - There is a significant relationship between personal services } \\
\text { (a dimension of CRM) and organizational productivity. }\end{array}$ \\
\hline Hypothesis supported & 0.000 & 0.463 & $\begin{array}{l}\text { - There is a significant relationship between system integration } \\
\text { (a dimension of CRM) and organizational productivity. }\end{array}$ \\
\hline Hypothesis supported & 0.000 & 0.425 & $\begin{array}{l}\text { - There is a significant relationship between organizational } \\
\text { culture (a dimension of CRM) and organizational productivity. }\end{array}$ \\
\hline
\end{tabular}

Investigation of the hypotheses reveals that all research hypotheses are supported. Furthermore, "personal services" dimension with a factor loading equal to 0.573 and significance number equal to 0.000 has the greatest relationship with organizational productivity. Further, technology dimension has the weakest relationship with organizational productivity in Ardebil Province Mellat Bank branches.

\section{Conclusion}

CRM is a concept which refers to all processes and technologies which are used for attraction, maintenance and serving customers in companies and organizations. CRM is a commercial strategy for selection and management of customers for optimization and improvement of corporate value and long-term sales increase. CRM is a comprehensive marketing strategy which integrates all processes, technology and business activities around customer. Results of analyses in the present research showed that technology is an important factor in productivity in mellat Bank. Therefore, managers are proposed to allocate appropriate budget to new technologies and applicationof technology to register and publish customers information and therefore improve relationships with customers. Concerning employees' dimension, it can be said that use of experienced and skilled workforce is a main source of competitive advantage in the contemporary organizations. Therefore, holding training courses, improvement of their motivation via incentives like salary increase, rewards and ..., high level of participation and cooperation and involvement in seminars and conferences can influence productivity. Concerning services personalization, it can be said that service personalization is one of the most important techniques in marketing mix. Considering the positive and significant impact of this dimension on organizational productivity, managers are proposed to hold periodical meetings with customers to identify their demands and register their needs in database. Further, serving customers based on their needs can improve productivity. Integration of systems is another important dimension of CRM which influences productivity. This dimension can be improved by providing employees with customers' information, rapid transfer of information to employees and use of systems for facilitation of such affairs. Furthermore, organizational culture is another important factor influencing productivity. Therefore, managers of Mellat Bank branches in Ardebil province are proposed to encourage their employees to participate and collaborate in decisions and tasks. Moreover, support for employees, clarification of vision and organizational targets and mission and ... can improve organizational culture and therefore improve organizational productivity.

\section{References}

Abbasi M, Torkaman M. Theoretical models of customer relationship management. Journal of Business 2010; 41: 4-8. [Article in Persian] Abdolvand, Mohammad Ali., Rahnama, Afshin., Mousavian, Seyed Javad., Hasanzadeh, Hafez., 2012. "Investigation of Effective Factors on Innovation and Knowledge Based Trust in Mobile Banking Adoption" Archive Dess Sciences, Vol 65, No. 7, $232-241$.

Abtahi, Hosein and Kazemi,Babak, 1996, "human resource training and improvement", institute for educational studies and planning, organization of development and revival of Iranian industries, second edition.

Aghazadeh, Hashem., Ganji Moghanlou, Hadi., Rahnama, Afshin., 2012. "Consideration of Relationship between Services Quality and Customers Satisfaction" Archive Dess Sciences, Vol 65, No. 5, 451-460.

Behi, Banafsheh, 2004, a framework for CRM software, master degree thesis, industrial engineering, technical and engineering faculty of TarbiyatModarres University.

Cascio, Wayne, 1998, Managing Human Resource; Productivity; Quality of Work Life, Fifth Edition, Irwin, McGraw-Hill 
Greenberg, Paul. (2001). Capturing and Keeping Customers in Internet Real Time, MacGraw-Hill.

Hoseini, Marziyeh, 2011, identification and ranking of factors affecting human resource productivity using fuzzy TOPSIS technique, master degree thesis, industrial management major, management faculty of Islamic Azad University, Central Tehran Branch.

Khoshpanjeh, Mahsa., Rahnama, Afshin., SeyyedKalan, Mir Mohammad., Hoseinpour, Ali., 2012. "Evaluating the Role of Spiritual Leadership Dimensions in Employee Empowerment and their Effect on Workforce Productivity" Journal of Basic and Applied Scientific Research, 2(8), 7681-7689.

Mostaghel, R. (2006). Customer Satisfaction Service Quality in Online Purchasing in Iran. Tarbiat Modares University, Tehran.

Omidvaran, Marziyeh, 2006; "identification of factors affecting CRM implementation in service firms (case study: Iranian Hoteling Industry", master degree thesis, Industrial engineering, Technical and Engineering faculty ofTarbiyatModarres University.

Peppard, J., 2000, Customer Relationship Management (CRM) in Financial Services, European Management Journal, Vol. 18, No. 3, pp. 312.327.

Piccoli, G., O'Connor, P., Capaccioli, C., Alvarez, R., 2003, Customer Relationship Management a Driver for Change in the Structure of the US lodging Industry.

Rahnama, Afshin., Alaei, Abbas., Shafaee, Javad., Ariana, Ali., 2012. "Evaluation of Relationship Marketing Dimension Effect on Degree of Customer's Loyalty of Insurance Industry in Iran" Journal of Basic and Applied Scientific Research, 2(2), 1842-1848.

Rahnama, Afshin., Alaei, Abbas., Shafaee, Javad., Hamdam, Hadi., 2012. "Evaluating the Impact of Banking Services Quality on Customer Loyalty in Mellat Bank Ardebil Province" Journal of Basic and Applied Scientific Research, 2(3), 2498-2506.

Rahnama, Afshin., Mousavian, Seyed Javad., Alaei, Abbas., Salimi Maghvan, Tavakkol., 2011. "The survey of relationship between creativity of staffs and organizational effectiveness" Australian Journal of Business and Management Research, Vol.1 No.6 [97104].

Reynolds, J., 2002, A practical guid to CRM: building more profitable customer relationship, CMP book, PP: 1-67.

Rezayeean, Ali; fundamentals of management and organization, Tehran, SAMT, 2010, $12^{\text {th }}$ printing.

Romano, N.C, and Fjermestad, J. (2002). "Electronic Customer Relationship Management, An Assessment of Research," International Journal of Ecommerce, Vol. 6, No. 3, pp. 59-111.

SamimiAmlashi, Naser, 2007, revision and development of Ocromodambi model for evaluation of preparedness of Iranian organizations for implementation of CRM, master degree thesis, industrial engineering, engineering and technical faculty of TarbiyatModarres University.

Shapiro, Carl, Varian, Hal, R., 1999, Information Rules, (Cambridge, MA: Harvard Business School Press.

Thompson, B. 2002, What is CRM? The customer relationship management primer, What you need to know to get started, published by www.CRMguru.com.

Tousi, Mohammad Ali; organizational culture, published by center for public management, 2003, $8^{\text {th }}$ printing.

Vazifehdoost, Hossein., Rahnama, Afshin., Mousavian, Seyed Javad., 2014. "Evaluation of the Impact of Brand Purchase Involvement, Satisfaction, Experience and Brand Trust on Loyalty to Brand" Mediterranean Journal of Social Sciences, Vol 5 No 20, 30543063.

Wells, J. D., Fuerst, W. L., Choobineh, J., 1999, Management information technology (IT) for one to one customer interaction information \& management., Information \& Management 35, 53-62. 